Review

\title{
Review of Studies on Technology-Enhanced Language Learning and Teaching
}

\author{
Rustam Shadiev * and Mengke Yang \\ School of Education Science, Nanjing Normal University, Nanjing 210097, China; 180621023@stu.njnu.edu.cn \\ * Correspondence: rustamsh@gmail.com
}

Received: 16 December 2019; Accepted: 8 January 2020; Published: 10 January 2020

check for updates

\begin{abstract}
In this study, we reviewed articles on technology-enhanced language learning and teaching. We aimed to summarize the content of reviewed articles in the following categories: (1) the number of articles published by journals and by year; (2) languages and skills; (3) technology used; (4) promising technologies. We reviewed 398 research articles. The highest number of articles was published in 2017 $(\mathrm{n}=80)$, whereas the lowest number was published in $2014(\mathrm{n}=53)$. The Computer Assisted Language Learning journal published the highest number of articles $(n=100)$, whereas the lowest number of published articles appeared in IEEE Transactions on Learning Technologies $(n=3)$. The most common target language was English $(n=267)$. Writing, speaking, and vocabulary gained the most attention in published articles. Twenty-three different technologies were identified and they were used 406 times. Based on our results, we made several implications and suggestions for future studies. This review study can serve as a guide for teaching and research communities who plan on designing language learning and teaching activities supported by technologies.
\end{abstract}

Keywords: language learning and teaching; technology; review

\section{Introduction}

Educators and researchers have applied technologies to assist language learning and instruction for many years. The Merriam-Webster Dictionary [1] defines technology as technical processes, methods, or knowledge used for accomplishing a task. Based on this definition, we define technology for the context of this study as accomplishing a learning task or instructional goal using technical processes, methods, or knowledge. For example, a learner may complete a speaking task by describing characteristics of an object in the target language and use a digital voice recorder to record her speech in order to play it later to her teacher.

The use of technologies in the classroom context was found to be no less effective than traditional classroom learning [2-6]. Several scholars reviewed related studies to identify what technologies were used and how they were effective for language learning and instruction. For example, Golonka et al. [3] provided a summary of evidence on the effectiveness of using technologies in language learning and teaching based on reviewed articles. The researchers focused on empirical studies that provided research-based evidence of the effectiveness of technology, in contrast to simple descriptions of technologies as well as their potential uses. Golonka and her colleagues found that there was lack of evidence of efficacy in reviewed articles. Studies focused on pronunciation training, assisted by technologies, provided strong support for technology to make a measurable impact in language learning and instruction. Many other studies had strong support regarding chat usage for language learning and instruction. In the review, evidence for claims that technology facilitated an improved learning performance of language learners in terms of output, interaction, feedback, affect, motivation, and metalinguistic knowledge was moderate [3]. 
In another study, Ghanizadeh et al. [2] reviewed articles on technology-enhanced language learning published between 2004 and 2014, to explore the effectiveness of using technology in improving language learning. Ghanizadeh et al. [2] found that technology was used in almost all areas of language education. Technology was useful in improving the quality of input, making communication authentic, and providing timely and relevant feedback. Ghanizadeh et al. [2] suggested that technology can support the development of all language skills (e.g., listening, writing, reading, speaking, grammar, and vocabulary). It was also found that learning environments created by utilizing technology were pleasant for student language learning.

There are also two review studies, one by Duman, Orhon, and Gedik [7] and the other by Shadiev, Hwang, and Huang [8]. Both studies reviewed articles related to mobile-assisted language learning. Duman et al. [7] analyzed articles published between 2000 and 2012, to investigate their characteristics and research trends. They found that the number of studies increased at a fast pace from 2008 and reached a peak in 2012. The most popular characteristic of the reviewed studies was teaching vocabulary with the use of cell phones and PDAs. Most studies were not based on any theoretical framework. In addition, the most frequently used methods were applied and design-based research with quantitative data analyses. Shadiev et al. [8] reviewed articles published between 2007 and 2016, to explore the trends in publications, their research focus, technology used, methodology, and current issues. Shadiev et al. [8] found an increasing trend in the publications. The most common research topics related to students' perceptions of technology and language proficiency. English was the most common target language. University and elementary school students were the most common participants in reviewed studies. Language learning activities were carried out in classroom and specified locations outside of campus, and most of the activities were based on instructor-centered approach. Finally, the scholars in reviewed studies mostly used qualitative and quantitative data.

The rapid technological advancement in recent years has provided educators with opportunities to use technology for education. Therefore, the use of technologies has become nearly ubiquitous for language learning. New technologies (e.g., virtual reality, augmented reality or wearable technology) were detected and increasingly available [9]. Furthermore, emerging technologies (e.g., cloud computing, computational thinking, natural language processing, etc.) are maturing and very promising to be used for language learning and instruction. Studies have shown that technology can promote the learning performance of language learners, increase learning motivation and providing them with more efficient means for language learning [5,6].

Nevertheless, technologies that are used for language learning and instruction are developing so fast that we need to be able to keep track of their applications and changes. Furthermore, some technologies become outdated and are never used again. Therefore, there is a need to review technologies applied to language learning and instruction more frequently and reconsider earlier, present and future practices.

Similar to Duman et al. [7], Ghanizadeh et al. [2], Golonka et al. [3], and Shadiev et al. [8], this study also reviewed articles related to technologies used for language learning. However, our review study is different from that of others. First, it covers a time range between 2014 and 2019 (December). Earlier review studies_for example, the research of Ghanizadeh et al. [2] and Golonka et al. [3] —-were published before 2014. Therefore, we reviewed articles published from 2014 until 2019 (December). Second, the scope of this review study is different. Our goal was to summarize the content of reviewed articles with respect to how many articles were published by journals and year, what languages and skills scholars focused on, what technologies were used and how, and what are promising technologies for future studies. Ghanizadeh et al. [2] and Golonka et al. [3] did not explore these issues, and Duman et al. [7] and Shadiev et al. [8] focused on mobile technologies.

This review can serve as a guide to language learners, teachers and researchers. That is, when an educator wants to apply new technology to assist instruction, this review paper can provide some useful information regarding what new technologies are, their advantages and disadvantages, and how they might be applied to language learning and teaching. 
In addition, we compared technologies used for a period between 2014 and 2019 with technologies used before 2014, to observe changes in technologies usage before and after 2014. For this comparison, we used results from our review research and those from the review study by Golonka et al. [3], because all technologies used by scholars and educators were listed in their article. We did not use the results from the review study by Ghanizadeh et al. [2], because they did not specify the technologies used but listed their general types, e.g., "ICT," "information technology," or "different kind of technology."

According to Machi and McEvoy [10], review studies provide an important source of information such as useful synthesis and original insights for the development of any field of science. Educators and researchers read such studies to improve their understanding of the field (e.g., what technologies were used to support language learning and instruction and how) and/or to make a contribution to the field (e.g., use new ideas for learning and instructional design or apply technologies in innovative ways). Because of the rapid technological development in recent years, some technologies become old and were never used again after 2014, whereas some new technology emerged and were used in the field for the last few years. There are also some technologies that were used both before 2014 and are still being used nowadays. Our comparison results can show changes in technology usage across different years (before and after 2014) and guide our decisions in selecting technologies for supporting learning and teaching activities in classroom. For example, according to Golonka et al. [3], an Internet forum or message board is a feasible tool and can be used in language learning for supporting student-to-teacher and peer-to-peer online asynchronous communication. However, we could not find any trace of this tool in articles published after 2014. Perhaps, after 2014, communication in the target language/s was arranged using different technologies, for example, instant messaging or social networking services-which are very popular among both young people and adults, and used in almost every part of our lives [11-13].

We addressed the following four research questions: (1) How many articles were published by journals and in what year? (2) What languages and skills scholars focused on in reviewed articles? (3) What technologies were used and how? (4) What are promising technologies for future language learning and instruction?

\section{Method}

The method of this review study followed the general recommendations of Creswell [14]. Research articles were searched from Web of Science database using the following search terms in different combinations: technology, language, learning, teaching, and instruction. We selected these terms because they were frequently used in previous review studies $[2,3,15]$. The following inclusion criteria were used for screening articles: (1) studies published between 2014 and 2019; (2) studies focused on using technologies for language learning and teaching; (3) studies published in English; (4) studies that were published as a full text in the top ten Social Sciences Citation Index (SSCI) journals related to educational technology. Articles published in SSCI journals usually undergo a rigorous reviewing process using stringent criteria and have high impacts in the field [7]. In total, 398 research articles were selected after the screening process.

Two researchers were involved in the selection process. All articles were examined by the researchers independently and those matching the above-mentioned criteria were selected. The researchers discussed any differences in the screening process until a consensus was reached. Besides the electronic search, the researchers manually searched for related articles in the targeted journals. Their manual search confirmed the articles selected through the electronic search. After articles were selected, the coding process took place. The same two researchers were involved in the coding process. They read article content, highlighted and coded the data of interest by labeling the concepts based on the themes of this review study. After that, the codes were grouped into categories and the properties of each category were identified independently. If a researcher identified more than one technology, each was counted separately. For example, when a learner watched video lectures and discussed their content with peers over instant messaging, a researcher would identify 
two technologies: video and instant messaging. Finally, the researchers finalized the coding phase through resolving the disagreements by re-examining the papers.

\section{Results}

Results of our review study are presented and discussed in the following categories: (1) the number of articles published by journals and year; (2) languages and skills; (3) technology used; (4) promising technologies. We provide an example for each finding in order to enhance the reader's comprehension of the findings.

\subsection{Published Articles by Journals and Years}

The number of articles published in each journal from 2014 to 2019 (December) is shown in Table 1. The results show that 2017 was the year when the highest number of articles was published $(n=80)$ whereas 2014 was the year with the lowest number of articles was published $(n=53)$. Computer Assisted Language Learning (CALL) published the highest number of articles $(n=100)$ and IEEE Transactions on Learning Technologies (IEEE TLT) published the lowest $(n=3)$.

Table 1. On Technology Assisted Language Learning from 2014 to 2019 (September).

\begin{tabular}{cccccccc}
\hline & $\mathbf{2 0 1 4}$ & $\mathbf{2 0 1 5}$ & $\mathbf{2 0 1 6}$ & $\mathbf{2 0 1 7}$ & $\mathbf{2 0 1 8}$ & $\mathbf{2 0 1 9}$ & Total \\
\hline CALL & 9 & 14 & 28 & 16 & 18 & 15 & 100 \\
LLT & 17 & 11 & 9 & 19 & 14 & 12 & 82 \\
ReCALL & 10 & 7 & 8 & 15 & 7 & 12 & 59 \\
SYSTEM & 5 & 6 & 6 & 7 & 3 & 11 & 37 \\
ET\&S & 4 & 6 & 4 & 8 & 13 & 1 & 36 \\
C\&E & 5 & 2 & 4 & 3 & 9 & 7 & 30 \\
ETR\&D & 1 & 6 & 1 & 2 & 5 & 3 & 17 \\
ILE & 0 & 4 & 6 & 4 & 1 & 3 & 17 \\
BJET & 2 & 2 & 1 & 5 & 2 & 2 & 14 \\
IEEE TLT & 0 & 0 & 2 & 1 & 0 & 0 & 3 \\
Total & 53 & 58 & 69 & 80 & 72 & 66 & 398 \\
\hline
\end{tabular}

\subsection{Languages and Skills}

Figure 1 presents the target language that research has focused on. English was the most commonly used target language in reviewed articles $(n=267)$. The second most common target language was Chinese $(n=24)$.

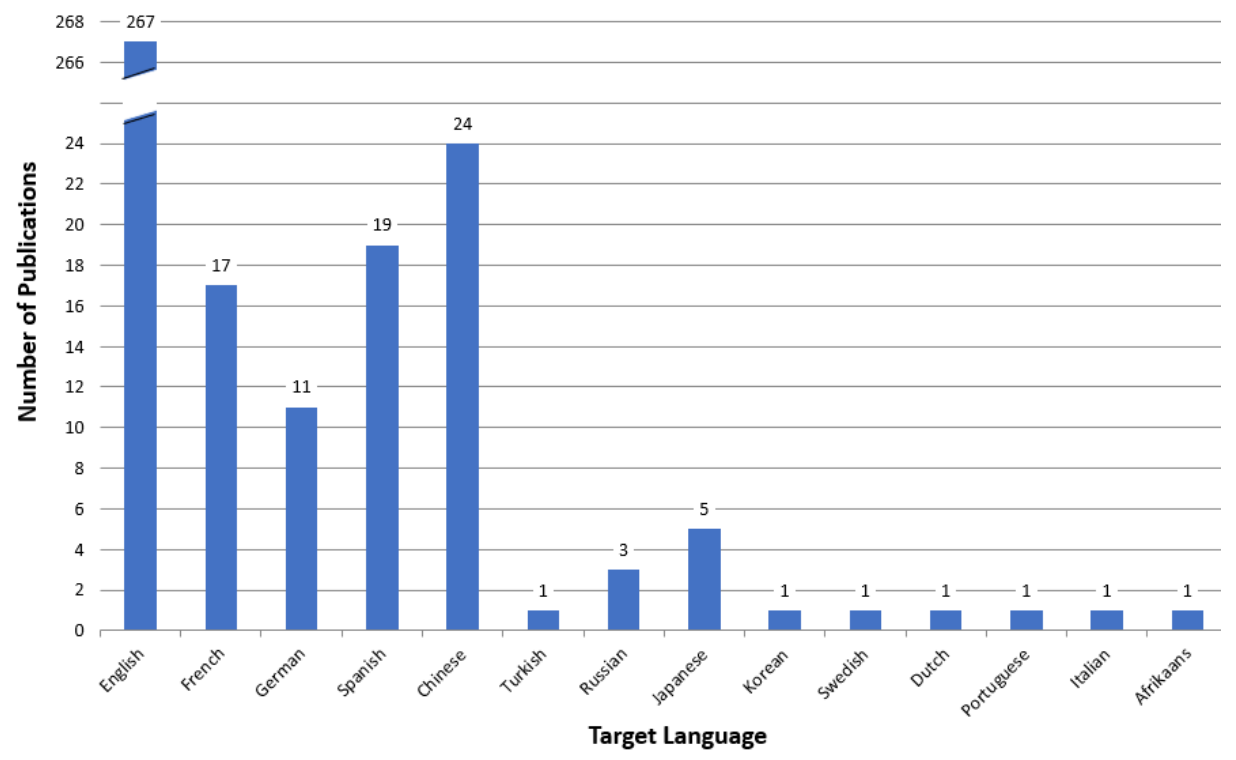

Figure 1. Target languages in reviewed articles. 
The researchers focused on improving different language skills, such as writing, vocabulary, speaking, reading, listening, grammar and phrases, using technology (Figure 2). In some studies, scholars focused on one single skill and in some others on more than one. As shown in Figure 2, researchers paid more attention to improving writing and speaking skills as well as vocabulary of language learners.

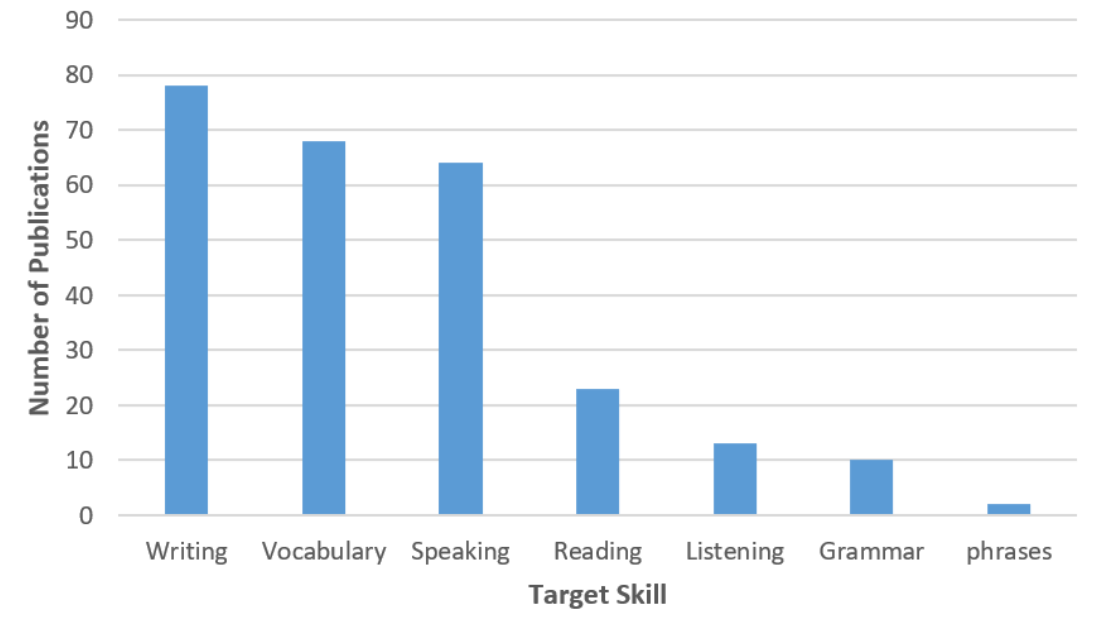

Figure 2. Language skills in reviewed articles.

\subsection{Technology}

The types of technology used in our reviewed articles are included in Table 2. In 398 articles, twenty-three kinds of technologies were used 406 times. Please note that there is a potential overlap in these categories, e.g., there are three technologies such as games, virtual reality, and wearables, and learners may play games in virtual reality using wearables or virtual reality can be found in game-based learning environment through wearables. In some articles, one technology was applied, and in other articles more than one technology was applied. However, in some articles, scholars did not identify the technology they used $(\mathrm{n}=48)$. For example, Şahin and Savran [16] developed an information and communication-based learning environment to support self-regulated vocabulary learning and Jiang, Renandya and Zhang [17] evaluated the design of one EFL multimedia courseware using the cognitive theory of multimedia learning; however, we were unable to determine what kind of technology the researchers used.

The most used technologies were games $(n=49)$ and online videos $(n=37)$. Nowadays, games are an important part of recreation time of most young adults [18]. In addition, games play a crucial role in their learning too [19]. It offers young adults interesting, convenient and creative ways to learn [20]. As for online videos, this media easily attracts learner attention and arouses the interest of language learners. With the continuous improvement of network coverage and capacity, video and audio transmission becomes very convenient. Language learners can finally share video or audio content of language learning resources conveniently. Yeh [21] explored the benefits of making multimodal films; the result showed that the video production process cultivated students' multiliteracies to different degrees and expanded their comprehension of the interplay between different symbolic resource modes of meaning construction.

Next, we compare between technologies used in articles published before 2014 and in articles published after 2014 (Table 3). We found that there are some technologies that were used before 2014 but never used after 2014 (i.e., old technologies). Tables 2 and 3 both include a course management system, white board, and digital library because they were used in 2014 but we could not find any trace of them in articles published after 2014. We also found some technologies were used before 2014 and after 2014 (technologies that are still in use); and we found that there are some technologies that were never used before 2014 but were after 2014 (new technologies). It is important to know that 
technologies still in use are not same as the old ones, but have become more powerful and have better and more affordances to assist learning.

Table 2. Technology used.

\begin{tabular}{|c|c|c|c|c|c|c|c|}
\hline $\begin{array}{ll}\text { Technology } & \text { Year } \\
\end{array}$ & 2014 & 2015 & 2016 & 2017 & 2018 & 2019 & Total \\
\hline Game & 6 & 7 & 6 & 11 & 14 & 5 & 49 \\
\hline Online video & 5 & 7 & 4 & 6 & 10 & 5 & 37 \\
\hline Collaborative writing & 3 & 9 & 8 & 5 & 3 & 7 & 35 \\
\hline Corpus & 8 & 5 & 9 & 5 & 2 & 3 & 32 \\
\hline Instant messaging & 2 & 4 & 4 & 11 & 5 & 5 & 31 \\
\hline Automated feedback & 6 & 4 & 4 & 4 & 5 & 6 & 29 \\
\hline Social networking & 1 & 6 & 4 & 10 & 7 & 1 & 29 \\
\hline Websites and digital resources & 3 & 2 & 5 & 6 & 3 & 6 & 25 \\
\hline Virtual reality & 0 & 5 & 2 & 4 & 6 & 2 & 19 \\
\hline Speech recognition & 0 & 3 & 5 & 4 & 3 & 3 & 18 \\
\hline Electronic gloss or annotation & 3 & 1 & 0 & 3 & 2 & 1 & 10 \\
\hline e-Books & 0 & 0 & 3 & 3 & 2 & 1 & 9 \\
\hline Electronic dictionary & 2 & 0 & 3 & 1 & 1 & 1 & 8 \\
\hline Intelligent tutoring system & 1 & 1 & 1 & 1 & 0 & 2 & 6 \\
\hline Voice recording & 2 & 0 & 0 & 1 & 2 & 1 & 6 \\
\hline Augmented Reality & 0 & 0 & 0 & 2 & 1 & 0 & 3 \\
\hline Robots & 0 & 1 & 1 & 0 & 1 & 0 & 3 \\
\hline Clicker & 0 & 0 & 0 & 0 & 1 & 2 & 3 \\
\hline Wearable devices & 0 & 0 & 1 & 0 & 1 & 0 & 2 \\
\hline Course management system & 2 & 0 & 0 & 0 & 0 & 0 & 2 \\
\hline Digital library & 1 & 0 & 0 & 0 & 0 & 0 & 1 \\
\hline White board & 1 & 0 & 0 & 0 & 0 & 0 & 1 \\
\hline Unidentified technology & 7 & 6 & 9 & 5 & 9 & 12 & 48 \\
\hline
\end{tabular}

Table 3. Comparison of technologies across different timeframes: old, still in use, and new technologies.

\begin{tabular}{ccc}
\hline Old & Still in Use & New \\
\hline Course management system & Game & Online video \\
White board & Corpus & e-Books \\
ePortfolio & Automated feedback & Voice recording \\
Internet forum or message board & Social networking & Augmented Reality \\
iPod & Instant messaging & Robots \\
Digital library & Virtual reality & Clicker \\
& Websites and digital resources & Wearable devices \\
& Speech recognition & \\
& Collaborative writing & \\
& Electronic gloss or annotation & \\
& Intelligent tutoring system & \\
& Electronic dictionary & \\
&
\end{tabular}

One should note that these results are from our review of articles which were selected based on specific criteria. Perhaps, results from articles selected using different criteria will be different.

In the following, we list and describe technologies that were used by scholars for language teaching and learning during 2014 to 2019.

\subsubsection{Game}

There are two types of games, those that are particularly developed for learning purposes and those that are designed purely for entertainment. They are often referred to as serious games or instructional games [22]. Serious games are characterized by a combination of consistent, serious aspects and playful elements of a video game [23]. Teachers can arrange games into learning activities 
and present learning contents on the game platform. Students are also allowed to practice language by playing games after class. It is found that with the help of serious game, learners learned more for less time and had better learning effectiveness than those who did not use games [24,25]. Games were applied for developing different language skills, e.g., vocabulary learning [26-28], pronunciation [29], listening and speaking skills [30]. In terms of 3D games, immersion was seen as an important factor. Neville [31] has researched the digital real-world context of waste management systems and recycling to instruct bi-directional prepositions and specialized vocabulary. It was found that immersion in the 3D game environment influenced the way language was invoked in learner written narratives.

However, it was found that game can lead to slight anxiety and mental effort [32].

\subsubsection{Corpus}

Corpus is recognized as powerful technology in language learning, because of its wide range of lexicographic resources [33]. Dash and Arulmozi [34] defined corpus as a collection of speeches, conversations, writings, etc., that students use to study and describe a language. For example, the London-Lund corpus consists of about 435,000 spoken British English words. It also contains 5000-word samples that adult, educated, professional people use in their daily life, including telephone and face-to-face conversations, discussions, lectures, and radio commentaries [35]. In Bardovi-Harlig, Mossman, and Vellenga [36], it is suggested that teachers build a corpus that matches the teaching objectives and provide resources for pragmatic teaching. Learning through guided corpus searches is also popular, as pragmatic routines and conventional expressions are particularly amenable to searches in a corpus [37]. It is found that writing and vocabulary learning are often considered as target language skills when using corpus. $\mathrm{Li}$ [38] investigated the role of direct corpus use in language learners' collocational competence in academic writing. The results showed that the use of corpora was useful in developing student collocational competence and raising their awareness of habitual collocational use. Ackerley [39] compared learning performance of students who used and who did not use a corpus. A wider range of genre appropriate phraseology usage was demonstrated by those who had used a corpus. Furthermore, a lower number of stock phrases were produced by these students. Daskalovska's [40] research also supports the positive role of direct corpus application in language context. Other language skills like reading and speaking were also noticed [37,41] although there were not so many examples, like for writing and vocabulary learning.

However, it was reported that students sometimes struggled with the interface and query syntax, they conducted inappropriate searches and misinterpreted data [39].

\subsubsection{Automated Feedback}

In this review study, automatic feedback refers to computer-supported corrective feedback. It is different from conventional face-to-face corrective feedback [42]. It substitutes feedback provided by the teacher [43]. After learners input language materials into the automated feedback system, it provides immediate feedback. For example, feedback can help solve problems in sentence-level grammar. Feedback can free the teachers as they are able to focus on higher-level problems (e.g., content and discourse). Learners can revise their work freely without consulting with teachers. Ranalli [44] pointed out explicitness as one important determining factor for learners to revise their mistakes. That is, generic feedback, compared to specific feedback, can require more mental-effort expenditure but it is less clear and helpful. The limitation of automated feedback is its one-size-fits-all nature and low accuracy rate. Because such feedback does not account for individual differences because its error types are not determined by pedagogical considerations but technological capacities [44]. Moreover, the evaluation and generation of discourse-related feedback is one big challenge for systems [45]. Although perfect accuracy is expected, it is difficult to achieve. 


\subsubsection{Social Networking}

Language learning through social networking sites (SNS) has attracted millions of users around the world. SNS are services that help learners create profiles and connect with others [46]. Language learners can construct a language identity, build a relationship with the target culture $[13,47]$ or join a closed language-learning organization that use SNS to enhance communication and the exchange of knowledge among learners [46].

Nowadays, Facebook, Twitter Instagram, etc., are popular social networking sites for language learning. Schreiber [48] studied the multilingual writing practice of a Serbian university student on Facebook. It showed how language learners use multiple varieties of English and Serbian, images, and video to shape their online identity and establish membership in local and global communities. Mompean and Fouz-González [49] studied the use of Twitter as a language learning and teaching tool for improving pronunciation. The results showed that students' pronunciation achieved positive progress and students also showed high participation in the learning process. Another popular social networking application, but in the Chinese-speaking community is WeChat. WeChat can be a powerful tool for non-Chinese native speakers who wish to learn Chinese. $\mathrm{Xu}$ and Peng [50] reported on an exploratory study investigating WeChat-assisted oral feedback in teaching Chinese as a second language (CSL). The results demonstrated that WeChat was beneficial in enhancing CSL learners speaking skills, and revealed positive attitudes of students.

Although research on social networking showed positive effect towards language learning, some issues were also reported. For example, Gao [12] warned that prolonged use of electronic devices to access SNS may cause health problems associated with vision. In addition, Chen [11] urged that language learners' attitudes towards social networking affected their learning practices. Therefore, it is important to instill a habit to use technology moderately. It is also critical to know how to make technology appeal to learners for both socializing and learning. Besides, privacy and surveillance are also serious problems.

\subsubsection{Instant Messaging}

Computer-mediated communication (CMC) is expected to address the problem of limited practicing opportunities, such as language writing and speaking in interaction [51]. Language learners may use instant messaging to create and send textual and voice content to their instructor or other learners. In addition, many instant messaging services feature voice call nowadays.

Hedayati and Foomani [52] suggested that it is possible that learning styles may affect student task performance, especially in synchronous CMC. Yeh and Lai [53] investigated how online tutoring may effect college students' meaning negotiation processes and speaking performance. The study found that students produced a rich language output through negotiation conversion, which meant that negotiation offered them a rich way to practice their oral skills through constant rephrasing and elaboration. Tang [54] compared the effects of the two task modalities, computer-mediated communication and face-to-face communication, on the pragmatic learning of Chinese modal verbs. Different from face-to-face interaction, communication though the computer features the visual saliency of text from chat as well as provides more time for processing; these two are beneficial for learners' modified output and focus-on-form [55]. However, the results showed that the face-to-face group outperformed the computer-mediated communication group at the immediate and delayed post-test. It was found that students-with the help of a computer-mediated communication group-frequently used abbreviated forms and symbols (e.g., smileys to convey their emotions and states), instead of using proper linguistic forms containing modals.

\subsubsection{Virtual Reality (VR)}

From a technical perspective, VR is defined as an immersive and interactive medium. It relies on manipulations of the visual, tactile, and aural senses mediated by computer [56]. From users' experience 
perspective, it is more of a psychological concept [57,58]. It is a computer-based environment in which a learner feels present [57]. Learners generally use headgear to enter the virtual world. An avatar is created in the VR for each learner, and then learners use it to walk through various locations and interact with other avatars in the target language [59].

Results of the reviewed studies showed many benefits of using VR for language learning. For example, Chen [60] found that VR resources provided language learners with visual and linguistic support and facilitated their language learning. Hassani, Nahvi, and Ahmadi [61] argued that, after using VR, there was an increase in the number of proper replies and proficiency level, but a decrease in the grammatical errors that students made. Shih [59] reported that learners' interest in the target culture was enhanced through the virtual platform. Yamazaki [62] revealed that students acquired contextualized communicative competence. In addition, their acquisition of incidentally encountered vocabulary was significantly improved.

It is suggested that using an immersive interface and simulated tasks with the help of virtual reality provides learners with authentic opportunities to practice target language [63]. Language learners can benefit from hypothetically real simulations in graphically dynamic and rich environments [64] as well as to immerse in contexts to practice language skills. Creating highly immersive environments using VR technology requires hardware support and VR devices are still relatively expensive.

\subsubsection{Websites and Digital Resources}

Websites and digital resources are a collection of public websites, personal websites and digital resources provided on the internet. Websites and digital resources have been recognized as important sources of linguistic and cultural knowledge for language learners to explore [65]. Learners can access the website through computers, mobile phones and other digital devices to get digital learning material.

Lim [66] explored the role of web portals in assisting student interpreters in the search for and collection of vocabulary. The results indicated that, by using websites and digital resources, language learners performed vocabulary building tasks more effectively by searching for the required vocabulary and were able to build larger and richer vocabulary combinations. The study also found that most students used websites with a specific focus rather than a general search engine [66]. Furthermore, Lim [66] reported the issue associated with information overload; it could frustrate the students.

\subsubsection{Speech Recognition (SR)}

Huang, Shadiev and Hwang [67] described SR as computer-based process during which oral speech is decoded and transcribed. A typical SR system receives sound input through a microphone, analyzes it using a pattern, model, or algorithm, and produces an output, usually in the form of text [68].

SR technology can provide attractive opportunities for oral practice and developing speaking skills. SR has great potential for providing feedback, so it is combined with automatic correction and feedback (ACF) technology, so that students can develop more autonomous pronunciation [68]. Scholars [69] proposed a system to provide oral practice of word order. The system used SR technology to process learners' responses and to detect errors in order to provide immediate corrective feedback on learners' errors. It was found that participants improved their proficiency in spoken skill of the target language. Research carried out by Huang et al. [67] confirmed the effectiveness of using speech to text recognition (SR) technology in the language classroom. With SR support, language learners performed better on comprehension tests than those who did not. SR technology can also be combined with computer-aided-translation technology to support cross-cultural communication [9]. Some problems associated with using SR technology were reported in reviewed articles. That is, one's accent, pronunciation, speed, or volume could cause low accuracy rates of SR. 


\subsubsection{Collaborative Writing Tools}

Collaboration ability is a basic requirement of society nowadays. Scholars suggested the following tools to enhance collaborative writing: wiki [70-73], Google Docs [74-76], blogs [77-79] and web-based word processing [80]. These tools are very popular and are used to practice writing and speaking skills $[77,81,82]$. Language learners can log on to collaborative writing tools to edit the same text, and the system will record the trace of each user. Participants in collaborative writing can edit documents at either the same or different time, face-to-face or remotely.

Collaborative writing tools provide useful features, including writing anywhere and viewing or reverting to previous versions of a text, as well as tracking the process of collaboration [83]. Teachers can use collaborative writing tools to help students develop their writing and speaking skills [84]. These tools can provide multiple functions such as sharing materials, communication, editing and collaborating on content $[85,86]$. Abrams [74] guided students, who took German as language class on creative writing, during their task to design a hypothetical ending for a German feature film using Google Docs. The results showed that the collaborative group produced more propositional content and better coherence than the non-cooperative group. Despite their advantages, some learners were concerned that their work among participants was not evenly distributed [87]. In the classroom, teachers hope that all language learners participate in collaborative writing, but actually not all participants are explicit collaborators [88]. The resistant collaborators showed lower participation, which could negatively impact contributions from other collaborators.

\subsubsection{Electronic Gloss or Annotation}

Annotations are defined as notes or glosses a learner makes to record thoughts or comments within a document [89]. Multimedia annotations are generally integrated into a software program and learners can choose the form of various lexical annotations provided by the software, such as text, audio, pictures and video animations, to annotate the target content [90]. The online annotation system also allows a group of readers to take notes on the same part of text, and provides readers with the opportunity to interact and learn from others within the same text context [91].

Research has shown that reading with gloss or annotation tools can improve the reading comprehension of foreign language learners in the online environment $[92,93]$. Ramezanali and Faez [90] examined which modes of gloss presentation (i.e., SL definition, aural, and video animation) are effective for learners' vocabulary learning and delayed word recollection. The findings revealed that dual glossing modes especially the dual glossing mode of L2 definition and video animation were more welcome and effective than single glossing modes for many test sessions. Hu, Vongpumivitch, Chang, and Liou, [94] compared the effects of the first and second language glosses. As a result, the group with higher language proficiency performed better on the posttest, and the higher-level group that received the language annotations remembered more words on the delayed posttest than the higher-level group that received the first language annotations.

\subsubsection{Intelligent Tutoring System (ITS)}

ITS is a computer-based educational system that provides individualized instructions like a human tutor [95]. Learners should show their advantages and disadvantages truthfully in ITS. Since the behavior of learners in ITS is recorded, ITS will decide what to teach and how to teach it according to the learning state of learners, in order to improve the learning effect.

Choi [96] developed a web-based ITS equipped with a process-oriented corrective feedback function and found that it may facilitate EFL learners' acquisition of grammatical concepts. The majority of participants showed favorable perceptions of the tutoring program. Allen, Crossley, Snow and McNamara [97] developed an ITS to provide SL students with clear writing strategy guidance and practice. Their results indicated that, interactions with the ITS led to an increase in writing performance 
and more positive attitudes towards the system. In addition, the results showed that a connection between student perceptions of the training system and game enjoyment exist [97].

\subsubsection{Electronic Dictionary}

Electronic dictionaries play an important role in understanding and learning online texts [98]. It is a kind of digital learning tool which converts the traditional printed dictionary into a digital one and allows for quick inquiry. When learners encounter unfamiliar words when reading foreign language texts, the dictionary can help them find their meanings and understand content $[99,100]$.

Karras [101] administered online dictionary learning training, and all participants exhibited a remarkable increase in vocabulary acquisition. The click-on word dictionary (CWD) and the key-in word dictionary (KWD) are considered the most commonly used dictionaries [102]. To use the key-in word dictionary, students need to type the word in the dictionary, while to use CWD, the students only need to click the word with the mouse. By contrast, learners spend less time separating their attention from the text when using CWD. Studies have demonstrated that learners tend to look up words in CWD than in KWD [103].

However, the benefit of using an electronic dictionary to learn words is limited. Because no one knows whether a learner selects a word meaning that fits the context well [104] within such a short time. In addition, the students' existing vocabulary size is also a key factor affecting the word search process and its effectiveness [98].

\subsubsection{Online Video}

Video is the recording of moving visual images made digitally or on videotape. Online video refers to video content delivered or available over the Internet. Learners can access language learning video resources through the internet and watch them to learn the target language. Lin and Wang [105] proposed that OER are an effective means and they can foster student multicultural competencies. They introduced two TED Talks into the EFL course. Students had to watch videos before and discuss it in class. The results showed that videos were particularly helpful for students to use communicative strategies and prepare carefully for multicultural communication. Yeh [21] explored the benefits which students perceived and associated with their multimodal film-making process. The video production process had cultivated students' multiliteracies to different degrees and expanded their comprehension of the interplay between different symbolic resource modes of meaning construction. Some researchers focused on the captions. The adaptive caption filtering approach proposed by Hsu [106] has proved that it may be an effective way to improve listening proficiency, because different students need different amounts of information to balance the listening comprehension. Hsu [107] found that the proportion of advanced words in writing was higher when watching video without captions than when watching video with captions before writing. Voice and video are vivid FL learning medium. However, many language learning films have captions in native language.

\subsubsection{E-Books}

A book which is composed in or converted to digital format for display on a computer screen or handheld device is an e-book. There is a difference between an e-book and a digital library; scholars $[108,109]$ consider a book in digital format for reading as an e-book, whereas a digital library is a collection of documents in digital format (i.e., not only books but also newspapers, magazines, papers, images, sound files, and videos) for reading, listening to and watching [110].

With the development of network technology, e-books as a teaching tool have been paid more and more attention in the language classroom [108]. Teachers can compile language learning materials into e-books so that students can have access to learning materials anytime and anywhere. Specific reading support cues, such as gloss and hypertext notes, have been embedded in e-books designed to promote language development [109]. 
However, a survey showed that most participants still thought that it was unpleasant to read the e-book, regardless of the reading purpose.

\subsubsection{Voice Recording}

Voice is considered as a method for communication using language and other semiotic means [111]. Recording is the use of recording equipment to record sound. Students can access online voice recording as an FL learning material or record their own voice as they practice speaking skill. Recorded audio can be used for comparison, rating, and corrective feedback. As for its effect on FL learning, Tecedor and Campos-Dintrans [112] investigated the effects of online voice recording activities and point-to-point video meetings conversations on the development of spoken language skills of primary Spanish learners. It was found that that both voice recording activities promoted fluency and complexity in tasks required presentational and interpersonal skills.

\subsubsection{Augmented Reality}

AR refers to a technology that integrates digital information and real environments and facilitates learner senses of reality. It has three characteristics: interaction in real time, integration of real and virtual worlds, and operation in 3D space [113]. Using a headset or mobile phone with AR technology, students can get virtual information about the object. For example, when students use AR technology to observe an apple, the word 'apple' will appear next to the apple, as well as the origin, taste and other information of the apple.

Using AR in the real world can effectively support students to achieve their learning goals [114]. Ho, Hsieh, Sun and Chen [115] employed AR in their study. A ubiquitous learning instruction system was developed for EFL learners to improve their performance. The results demonstrated positive effects of using AR; it improved learning performance. Hsu [114] developed two learning game systems based on AR to learn English vocabulary in contextual surroundings. Results showed that AR enabled ubiquitous and situated learning. In addition, learners perceived sense of presence and immediacy. In addition, such skills as problem solving, information management, and reflection were enhanced. Motivation was also improved.

\subsubsection{Robots}

Merriam-Webster Dictionary [1] defines robot as a machine that resembles a living creature. Robots are capable of moving and performing various actions. An anthropomorphic robot is considered as a useful educational tool because of its ability to improve teaching efficiency and learning motivation [116]. It is found that robot-supported language learning is generally applied to younger learners. Mazzoni and Benvenuti [117] carried out one study with a humanoid robot; it acted as a partner for language learners. Robots and learners collaborated on a word-picture association task involving vegetables and fruits to help learn English words. Wu, Wang and Chen [118] carried out a study in which they investigated how teaching assistant robots can help in elementary school. The robot is able to perform different forms of interaction with students (e.g., gestures or facial expression). Besides, physical activity was designed to engage and entertain students, while enhancing their interest in learning through speaking and reacting [118]. Human-like or cartoon-like external appearances of robots plays an important role in their acceptance when used for young learners. A familiar, interesting appearance is effective to learners who afraid to speak in English in front of peers [118].

\subsubsection{Clicker}

Clickers are keypads and they are used by students to respond to the lecturer's questions [119]. Web-enabled mobile tools (e.g., smart phones or tablets) has been used to replicate clicker-based classroom polling [120].

Answering questions by using clickers can be anonymous, so learners can give their own answers without pressure. Roussel and Galan [121] compared the effects of using clickers versus raising hands 
on language learning in class. It was found that using clickers could reduce the cognitive load caused by learning new terms and new content, and thus improve language learning performance. Kent [122] proposed that the integrated classroom of student response system (SRS) or clicker could provide an environment for learning and opportunities for active learning, especially when combined with peer interaction technologies. In addition, learners are willing to accept SRS as an alternative to traditional methods, believing that it can help highlight their knowledge gap, focus their attention and stimulate their participation. However, compared with the traditional computer-mouse interface, the clicker has not shown a better promotion effect.

\subsubsection{Wearable Devices}

A wearable device is worn as clothing or accessories. These devices record and report information about behavior, e.g., sleep patterns/physical activity. Therefore, these devices can motivate and educate learners to adopt good habits and improve their health [123]. Wearable devices have been popular in education for some time; head-mounted displays or Google Glasses have gained much attention by researchers [124]. Scholars [125] created language learning scenarios using wearable technologies, i.e., with everyday objects and friendly interfaces. Teachers can focus on creating friendly learning environments, as well as encourage students' participation instead of keeping records of what students are doing and how well they perform. Smartwatch-supported learning activity was designed in Shadiev, Hwang and Liu [126]. The language learning process was combined with physical exercise: students learned in their local community and were physically active (e.g., by walking) at the same time. Smartwatch applications such as texting, voice recording, vocabulary, etc. supported language learning and fitness tracker monitored and reported student physical activity in real time. The results showed that smartwatches were useful for language learning. The students perceived that the learning activity designed in the study was useful for their positive emotions and health. The research revealed the following advantages of smartwatches: wireless connectivity-it allowed students to seamlessly access learning information and interact with teachers and classmates; multimedia tools-they enabled students create learning content; feedback or notifications-they were provided in a timely manner encouraged students to learn on time and push them to practice language or exercise physically when necessary. However, the screen size of the smartwatch was too small, so it was inconvenient to make textual input through typing.

\section{Discussion and Conclusions}

In this study, we reviewed 398 articles on technology-assisted language learning. First, we reported how many articles were published by journals and year. Second, we discussed different languages and skills that reviewed articles focused on. Third, we explained about twenty-three technologies that were used and gave some examples (see the Technology Used section). We also discussed technology-related issues, their solutions and promising technologies for future studies.

Our results showed that the most articles were published in journals such as CALL, Language Learning and Technology (LLT), ReCALL, and System. These journals focus on language learning, teaching, and testing supported by technology. It means that the aim and scope of these journals fit our research topic more closely. CALL published more articles related to our topic compared to ReCALL and LLT journals, probably because CALL publishes eight issues per year, whereas ReCALL and LLT publish only three issues per year. Similar findings were reported elsewhere. For example, Shadiev et al. [8] mentioned CALL and Zhao [15] mentioned the System and Language Learning and Technology journals as those that publish articles related to technology-assisted language learning more frequently than others. This finding affirmed the contribution of CALL, LLT, ReCALL, and the System journals on the topic of technology-assisted language learning and teaching. Golonka et al. [3] —who also reviewed articles related to technology-assisted language learning—did not explore this aspect.

The results showed that English and Chinese were the most common target languages. In addition, we found that English was studied about ten times more than Chinese. One possible reason for such a 
finding is that English and Chinese are the most popular and widely spoken languages in the world nowadays. Ghanizadeh et al. [2] and Shadiev et al. [8] also confirmed this finding in their review study. Although, Zhao [15] claimed that whilst English was among commonly studied languages, he found that French and Spanish were the most studied languages, and Chinese was not in the list of frequently used languages. Golonka et al. [3] did not explore this issue.

This finding suggests that educators and researchers may find more resources related to English and Chinese published in top SSCI journals. Other languages received very little attention from the research community, even though they are unique and special in their own ways. Therefore, educators and researchers may consider focusing on those underexplored languages in the future as well.

According to our results, scholars paid more attention to language output-i.e., writing and speaking skills. One possible reason for this finding is that traditional classrooms emphasize language input far more than output. Traditional classroom instruction focuses on listening and reading skills using traditional methods (e.g., textbook, notebook, and pen). Therefore, researchers aimed to facilitate language output using technology because it could support learners to produce language output through writing and speaking. Another possible reason is because writing and speaking activities are much easier to implement with technological support.

Unfortunately, our findings related to language skills cannot be compared with those from earlier research, because previous review studies $[2,3,15]$ did not explore this aspect.

In terms of technology usage, we found that twenty-four technologies were employed in reviewed studies. All of these technologies were listed and we gave some examples on how they were applied to support language learning along with obtained results. According to our findings, most studies reported positive results. That is, learners had better outcomes when their learning was supported by technology. In addition, learners had positive perceptions towards the technology used. This shows that technology was effective in supporting language learning and learners accepted and used it. The finding related to the effectiveness of technology application to support language learning and instruction is in line with earlier review studies because Duman et al. [7], Ghanizadeh et al. [2], Golonka et al. [3], Shadiev et al. [8], and Zhao [7] reported similar results.

The use of technology can improve learners' motivation and interest. Technology provides language learners with target language input, output, and feedback; it also provides an effective way for teachers to organize course content and interact with multiple students. In any case, the use of technology is encouraged and teachers can adjust their teaching activities as well as change their teaching strategies to make the most effective use of existing resources. We suggest caution in the use of technology to assist language learning and teaching. When technology is used to promote learning and teaching, objectives rather than technical means should be the priority. Learners or teachers can refer to the technical manual and learn from experiences reported in related studies, so as to highlight the advantages of the technology and avoid its disadvantages.

In addition, we identified old, current, and new technologies used for language learning. These results show changes in technology usage, from the period before 2014 to the period after 2014. They can guide the decisions of educators and researchers to select technologies for supporting learning and teaching activities in their classrooms. In addition, we can see from Table 2 that there is abundant theoretical and practical knowledge related to technologies that are still in use, e.g., 49 game-based studies were carried out. Such knowledge can inform educators and researchers to design studies with similar learning and instructional design and/or application of similar technologies. On the other hand, the field lacks theoretical and practical knowledge related to new technologies, e.g., the use of wearable devices was reported in two studies only. Therefore, educators and researchers may contribute to the field by adding new knowledge through carrying more studies related to new technologies.

Based on our results, we discuss promising technologies for future language learning, and give some suggestions to educators and researchers. For future research, we recommend educators and researchers use the new technologies reported in Table 3. Scholars have also recently started using these technologies. In addition, we suggest considering other technologies that were not included in 
this review study, as they are emerging, powerful, and promising in the area of language learning-for example, cloud computing, natural language processing, air three-dimensional imaging technology, computational thinking, etc. Nowadays, these technologies are used in different fields, e.g., medicine, education, business, etc. They may also perform well in the field of language learning. For example, cloud computing may help achieve the large-scale sharing of educational resources for collaborative language learning without taking up too much of the device's memory. We believe they are still maturing and did not receive a lot of attention from many scholars in the field of language learning. However, we cannot deny that new technologies can become a critical source in promoting learning in the future.

Scholars grouped technologies into several categories. For example, Golonka et al. [3] suggested that technologies can be used as technologies for individual study, classroom-based tools, mobile devices, and network-based social computing. Zhao [15] suggested that technologies can be used for access to materials, as communication opportunities, for feedback, and as those integrated in the language classroom. Our review results show that nowadays technologies have matured and feature multiple, sophisticated functions, such that their relation to the above-mentioned categories overlaps and it is hard for someone to group them into one single category. For example, Golonka et al. [3] suggested that electronic gloss or annotation is an individual study tool. However, in the study by Yeh et al. [91], learners used this tool not only for individual purpose, but for collaborative work as well. That is, learners annotated the same part of text, interacted with and learned from others within the same text context [91].

We also list several issues associated with technology usage and provide possible solutions to address them. One general issue that we noticed from our review is that some scholars did not identify the technology they used; neither did they report any problems during their research. This information is important because it can help other educators and researchers. First, educators and researchers would better understand what kind of technology was used for that particular study, and how it was implemented so that the reported results were obtained. Second, knowing what problems learners, educators, and researchers experienced during that particular study will help avoid them such issues or learn how to address them. Therefore, we recommend that researchers provide such important details in their articles in the future.

Some issues were reported in the reviewed studies that led to inappropriate inputs, superficial interactions, and inaccurate feedback. Some other problems were students' frustration with software and hardware, or distraction from learning tasks. We tried to provide related suggestions on how to address these problems. One such issue is that learners are not aware of how to use technology more efficiently for their language learning. Ziegler [55] found that, during computer-mediated communication which was aimed at improving writing skills, students frequently used abbreviations and symbols (e.g., smileys to convey their emotions and states), instead of using proper linguistic forms containing modals. For this reason, learners did not practice writing skills well. Lim [66] reported that when learners worked on their vocabulary building tasks to search the internet for relevant vocabulary, sometimes they were discouraged by information overload. Tono [104] argued that learners, especially those with a small vocabulary size, when using electronic dictionary may select inappropriate translated words or meanings that do not fit the context. These issues suggest that learners need to be given proper guidance and effective learning strategies. For example, for the first case, the instructor may suggest to learners to use more proper linguistic forms instead of abbreviations and symbols in order to develop their writing skills. In the second case, the instructor may give guidance about the most relevant websites and effective search strategies. In the case of using an electronic dictionary, we suggest that learners take their time to choose the right word meaning according to the context. When encountering unfamiliar words, they need to guess its meaning according to the context and then use electronic dictionaries to verify.

Some studies reported on the negative effects from the use of technology on learners well-being; such as physical discomfort, negative emotions, cognitive load, and so on. Zhonggen [32] warned that 
learners may feel anxious if they play learning games for too long, which may pose a threat to learning effectiveness. Learners in Gao [12] were concerned about using social networking sites for a long time as it could hurt their eyes. In addition, it is possible that they may fall into the abyss of addiction after using networking sites or playing games for too long a time. Internet violence was also one of the problems that students encountered. Therefore, it is necessary to educate learners to be careful not to become addicted and teach them how to control their technology usage.

Learners may have some technological problems when using technology because of their skills. If timely and relevant support is not provided, then learners will likely have negative perceptions of technology and waste their time. Therefore, in case of experiencing technical issues, instant feedback needs to be provided. Furthermore, learners need to be given enough time to train on the technology to know how to operate it better, as well as its advantages and disadvantages in order to use it for learning more effectively [126].

Although perfect accuracy of technology is expected, it is difficult to achieve. For example, Huang et al. [67], McCrocklin [68], Shadiev et al. [9] reported that the accuracy rate of speech recognition is a problematic issue during the learning process. If output generated by recognition systems is not accurate enough, then it is not useful, and is meaningless for learners. Therefore, it is suggested that recognition technologies need to be trained on and that efficient strategies must be used during the recognition process.

Learner proficiency levels also need to be considered during learning processes supported by technology. For example, learners need to be given control of what level of learning content to use that matches their proficiency level best [92]. Otherwise, learning content can be either too difficult or too easy and inefficient for learning. Hsu [106] proposed the adaptive caption filtering approach and it was effective in improving listening proficiency, because students could select different amounts of information with different difficulty levels. We also suggest that captions in foreign language or first language can be provided during films, lectures, academic talks, etc., in different proportions-to meet the needs of language learners at different levels (e.g., more captions should be displayed for learners with a lower language ability). When learners use annotation tools, we recommend that low-proficiency level learners use their first language to take notes and with the improvement of their proficiency, they may be able to better use L2 concept links for word memory and learning [92].

Some tools, such as Virtual Reality hardware support and devices, are still relatively expensive for some educators and researchers. Perhaps, some other alternatives can be searched for. For example, VR can be created by some inexpensive tools such as Samsung VR, Samsung 360-degree camera, and Samsung smart phones.

We hope that when teachers and researchers plan to use technologies for language learning and instruction, our results and suggestions can be useful to guide them.

There is one limitation that we need to acknowledge. That is, many papers on using technologies for language learning that were published in conferences (e.g., Computer Assisted Language Learning) and some other well-known journals (e.g., CALICO journal) were not included in this review. The reason we focus on selected SSCI journals is because they rank high and are highly relevant to the topic of technical support for language learning. These ten journals are usually reviewed using rigorous and stringent criteria, and have high impacts in the field. Therefore, in future studies, we may review papers published in conference proceedings and other journals, to provide more extensive and detailed information.

Author Contributions: Methodology, Conceptualization, Investigation, Formal Analysis, M.Y. and R.S.; Original Draft Preparation, M.Y.; Review and Editing, R.S.; Supervision, R.S. All authors have read and agreed to the published version of the manuscript.

Funding: This research received no external funding.

Conflicts of Interest: There is no conflict of interest. 


\section{References}

1. Merriam-Webster Dictionary; Merriam-Webster, Inc.: New York, NY, USA, 2016; Available online: https: //www.merriam-webster.com/dictionary/ (accessed on 10 December 2019).

2. Ghanizadeh, A.; Razavi, A.; Jahedizadeh, S. Technology-Enhanced Language Learning (TELL): A Review of Resourses and Upshots. Int. Lett. Chem. Phys. Astron. 2015, 54, 73. [CrossRef]

3. Golonka, E.M.; Bowles, A.R.; Frank, V.M.; Richardson, D.L.; Freynik, S. Technologies for foreign language learning: A review of technology types and their effectiveness. Comput. Assist. Lang. Learn. 2014, 27, 70-105. [CrossRef]

4. Grgurović, M.; Chapelle, C.A.; Shelley, M.C. A meta-analysis of effectiveness studies on computer technology-supported language learning. ReCALL 2013, 25, 165-198. [CrossRef]

5. Jin, L. Digital affordances on WeChat: Learning Chinese as a second language. Comput. Assist. Lang. Learn. 2018, 31, 27-52. [CrossRef]

6. Shadiev, R.; Huang, Y.M. Investigating student attention, meditation, cognitive load, and satisfaction during lectures in a foreign language supported by speech-enabled language translation. Comput. Assist. Lang. Learn. 2019, 1-26. [CrossRef]

7. Duman, G.; Orhon, G.; Gedik, N. Research trends in mobile assisted language learning from 2000 to 2012. ReCALL 2015, 27, 197-216. [CrossRef]

8. Shadiev, R.; Hwang, W.W.; Huang, Y.M. Review of research on mobile language learning in authentic environments. Comput. Assist. Lang. Learn. 2017, 30, 284-303. [CrossRef]

9. Shadiev, R.; Sun, A.; Huang, Y.M. A study of the facilitation of cross-cultural understanding and intercultural sensitivity using speech-enabled language translation technology. Br. J. Educ. Technol. 2019, 50, 1415-1433. [CrossRef]

10. Machi, L.A.; McEvoy, B.T. The Literature Review: Six Steps to Success, 2nd ed.; Corwin Press: Thousand Oaks, CA, USA, 2012.

11. Chen, H.I. Identity practices of multilingual writers in social networking spaces. Lang. Learn. Technol. 2013, 17, 143-170.

12. Gao, Y. An Analysis of Social Media Use Within and Outside of College English Classes in China. Available online: https://ir.lib.uwo.ca/etd/6004/ (accessed on 10 December 2019).

13. Klimanova, L.; Dembovskaya, S. L2 identity, discourse, and social networking in Russian. Lang. Learn. Technol. 2013, 17, 69-88.

14. Creswell, J.W. Research Design: Qualitative, Quantitative, and Mixed Methods Approaches, 4th ed.; Sage: Los Angeles, CA, USA, 2014.

15. Zhao, Y. Recent developments in technology and language learning: A literature review and meta-analysis. CALICO J. 2003, 21, 7-27. [CrossRef]

16. Şahin Kızıl, A.; Savran, Z. Assessing self-regulated learning: The case of vocabulary learning through information and communication technologies. Comput. Assist. Lang. Learn. 2018, 31, 599-616. [CrossRef]

17. Jiang, D.; Renandya, W.A.; Zhang, L.J. Evaluating ELT multimedia courseware from the perspective of cognitive theory of multimedia learning. Comput. Assist. Lang. Learn. 2017, 30, 726-744. [CrossRef]

18. Chen, C.P. Understanding mobile English-learning gaming adopters in the self-learning market: The Uses and Gratification Expectancy Model. Comput. Educ. 2018, 126, 217-230. [CrossRef]

19. Skierkowski, D.; Wood, R.M. To text or not to text? The importance of text messaging among college-aged youth. Comput. Hum. Behav. 2012, 28, 744-756. [CrossRef]

20. Huang, R.T.; Jang, S.J.; Machtmes, K.; Deggs, D. Investigating the roles of perceived playfulness, resistance to change and self-management of learning in mobile English learning outcome. Br. J. Educ. Technol. 2012, 43, 1004-1015. [CrossRef]

21. Yeh, H.C. Exploring the perceived benefits of the process of multimodal video making in developing multiliteracies. Lang. Learn. Technol. 2018, 22, 28-37.

22. Butler, Y.G. The use of computer games as foreign language learning tasks for digital natives. System 2015, 54, 91-102. [CrossRef]

23. Alvarez, J.; Djaouti, D. An introduction to Serious Game Definitions and concepts. Serious Games Simul. Risks Manag. 2011, 11, 11-15. 
24. Sandberg, J.; Maris, M.; Hoogendoorn, P. The added value of a gaming context and intelligent adaptation for a mobile learning application for vocabulary learning. Comput. Educ. 2014, 76, 119-130. [CrossRef]

25. Usai, F.; O'Neil, K.G.; Newman, A.J. Design and empirical validation of effectiveness of LANGA, an online game-based platform for second language learning. IEEE Trans. Learn. Technol. 2017, 11, 107-114. [CrossRef]

26. Chen, C.M.; Liu, H.; Huang, H.B. Effects of a mobile game-based English vocabulary clearning app on learners' perceptions and learning performance: A case study of Taiwanese EFL learners. ReCALL 2019, 31, 170-188. [CrossRef]

27. Calvo-Ferrer, J.R. Educational games as stand-alone learning tools and their motivational effect on L 2 vocabulary acquisition and perceived learning gains. Br. J. Educ. Technol. 2017, 48, 264-278. [CrossRef]

28. Castañeda, D.A.; Cho, M.H. Use of a game-like application on a mobile device to improve accuracy in conjugating Spanish verbs. Comput. Assist. Lang. Learn. 2016, 29, 1195-1204. [CrossRef]

29. Schremm, A.; Hed, A.; Horne, M.; Roll, M. Training predictive L2 processing with a digital game: Prototype promotes acquisition of anticipatory use of tone-suffix associations. Comput. Educ. 2017, 114, 206-221. [CrossRef]

30. Hwang, W.Y.; Shih, T.K.; Ma, Z.H.; Shadiev, R.; Chen, S.Y. Evaluating listening and speaking skills in a mobile game-based learning environment with situational contexts. Comput. Assist. Lang. Learn. 2016, 29, 639-657. [CrossRef]

31. Neville, D.O. The story in the mind: The effect of 3D gameplay on the structuring of written L2 narratives. ReCALL 2015, 27, 21-37. [CrossRef]

32. Zhonggen, Y. Differences in serious game-aided and traditional English vocabulary acquisition. Comput. Educ. 2018, 127, 214-232. [CrossRef]

33. Frankenberg-Garcia, A.; Lew, R.; Roberts, J.C.; Rees, G.P.; Sharma, N. Developing a writing assistant to help EAP writers with collocations in real time. ReCALL 2019, 31, 23-39. [CrossRef]

34. Dash, N.S.; Arulmozi, S. Definition of 'Corpus'. In History, Features, and Typology of Language Corpora; Springer: Singapore, 2018; pp. 1-15.

35. Stubbs, M. Words and Phrases: Corpus Studies of Lexical Semantics; Blackwell Publishers: Oxford, UK, 2001.

36. Bardovi-Harlig, K.; Mossman, S.; Vellenga, H.E. The effect of instruction on pragmatic routines in academic discussion. Lang. Teach. Res. 2015, 19, 324-350. [CrossRef]

37. Bardovi-Harlig, K.; Mossman, S.; Su, Y. The effect of corpus-based instruction on pragmatic routines. Lang. Learn. Technol. 2017, 21, 76-103.

38. Li, S. Using corpora to develop learners' collocational competence. Lang. Learn. Technol. 2017, 21, $153-171$.

39. Ackerley, K. Effects of corpus-based instruction on phraseology in learner English. Lang. Learn. Technol. 2017, 21, 195-216.

40. Daskalovska, N. Corpus-based versus traditional learning of collocations. Comput. Assist. Lang. Learn. 2015, 28, 130-144. [CrossRef]

41. Hadley, G.; Charles, M. Enhancing extensive reading with data-driven learning. Lang. Learn. Technol. 2017, 21, 131-152.

42. Rassaei, E. Computer-mediated text-based and audio-based corrective feedback, perceptual style and L2 development. System 2019, 82, 97-110. [CrossRef]

43. Li, J.; Link, S.; Hegelheimer, V. Rethinking the role of automated writing evaluation (AWE) feedback in ESL writing instruction. J. Second. Lang. Writ. 2015, 27, 1-18. [CrossRef]

44. Ranalli, J. Automated written corrective feedback: How well can students make use of it? Comput. Assist. Lang. Learn. 2018, 31, 653-674. [CrossRef]

45. Saricaoglu, A. The impact of automated feedback on L2 learners' written causal explanations. ReCALL 2019, 31, 189-203. [CrossRef]

46. Maier, C.; Laumer, S.; Eckhardt, A.; Weitzel, T. Giving too much social support: Social overload on social networking sites. Eur. J. Inf. Syst. 2015, 24, 447-464. [CrossRef]

47. Blattner, G.; Fiori, M. Virtual social network communities: An investigation of language learners' development of sociopragmatic awareness and multiliteracy skills. CALICO J. 2011, 29, 24-43. [CrossRef]

48. Schreiber, B.R. "I am what I am": Multilingual identity and digital translanguaging. Lang. Learn. Technol. 2015, 19, 69-87.

49. Mompean, J.A.; Fouz-González, J. Twitter-based EFL pronunciation instruction. Lang. Learn. Technol. 2016, $20,166-190$. 
50. Xu, Q.; Peng, H. Investigating mobile-assisted oral feedback in teaching Chinese as a second language. Comput. Assist. Lang. Learn. 2017, 30, 173-182. [CrossRef]

51. Sydorenko, T.; Daurio, P.; Thorne, S.L. Refining pragmatically-appropriate oral communication via computer-simulated conversations. Comput. Assist. Lang. Learn. 2018, 31, 157-180. [CrossRef]

52. Hedayati, M.; Foomani, E.M. Learning style and task performance in synchronous computer-mediated communication: A case study of Iranian EFL learners. Educ. Technol. Soc. 2015, 18, 344-356.

53. Yeh, H.C.; Lai, W.Y. Speaking progress and meaning negotiation processes in synchronous online tutoring. System 2019, 81, 179-191. [CrossRef]

54. Tang, X. The effects of task modality on L2 Chinese learners' pragmatic development: Computer-mediated written chat vs. face-to-face oral chat. System 2019, 80, 48-59. [CrossRef]

55. Ziegler, N. Synchronous computer-mediated communication and interaction: A meta-analysis. Stud. Second Lang. Acquis. 2016, 38, 553-586. [CrossRef]

56. Dennen, V.P.; Branch, R.C. Considerations for Designing Instructional Virtual Environments. Available online: https://eric.ed.gov/?id=ED391489 (accessed on 10 December 2019).

57. Biocca, F. Communication within virtual reality: Creating a space for research. J. Commun. 1992, 42, 5-22. [CrossRef]

58. Steuer, J. Defining virtual reality: Dimensions determining telepresence. J. Commun. 1992, 42, 73-93. [CrossRef]

59. Shih, Y.C. A virtual walk through London: Culture learning through a cultural immersion experience. Comput. Assist. Lang. Learn. 2015, 28, 407-428. [CrossRef]

60. Chen, J.J. Enhancing Student Engagement and Interaction in E-Learning Environments through Learning Analytics and Wearable Sensing. Ph.D. Thesis, Hong Kong Baptist University, Hong Kong, China, 2016. Open Access Theses and Dissertations. Available online: http://repository.hkbu.edu.hk/etd_oa/287 (accessed on 10 December 2019).

61. Hassani, K.; Nahvi, A.; Ahmadi, A. Design and implementation of an intelligent virtual environment for improving speaking and listening skills. Interact. Learn. Environ. 2016, 24, 252-271. [CrossRef]

62. Yamazaki, K. Computer-assisted learning of communication (CALC): A case study of Japanese learning in a 3D virtual world. ReCALL 2018, 30, 214-231. [CrossRef]

63. Park, M. Innovative assessment of aviation English in a virtual world: Windows into cognitive and metacognitive strategies. ReCALL 2018, 30, 196-213. [CrossRef]

64. Dalgarno, B.; Lee, M.J. What are the learning affordances of 3-D virtual environments? Br. J. Educ. Technol. 2010, 41, 10-32. [CrossRef]

65. Shen, H.; Yuan, Y.; Ewing, R. English learning websites and digital resources from the perspective of Chinese university EFL practitioners. ReCALL 2015, 27, 156-176. [CrossRef]

66. Lim, L. Engaging student interpreters in vocabulary building: Web search with computer workbench. ReCALL 2014, 26, 355-373. [CrossRef]

67. Huang, Y.M.; Shadiev, R.; Hwang, W.Y. Investigating the effectiveness of speech-to-text recognition applications on learning performance and cognitive load. Comput. Educ. 2016, 101, 15-28. [CrossRef]

68. McCrocklin, S.M. Pronunciation learner autonomy: The potential of automatic speech recognition. System 2016, 57, 25-42. [CrossRef]

69. De Vries, B.P.; Cucchiarini, C.; Bodnar, S.; Strik, H.; van Hout, R. Spoken grammar practice and feedback in an ASR-based CALL system. Comput. Assist. Lang. Learn. 2015, 28, 550-576. [CrossRef]

70. Hsu, H.C.; Lo, Y.F. Using wiki-mediated collaboration to foster L2 writing performance. Lang. Learn. Technol. 2018, 22, 103-123.

71. Zou, B.; Wang, D.; Xing, M. Collaborative tasks in Wiki-based environment in EFL learning. Comput. Assist. Lang. Learn. 2016, 29, 1001-1018. [CrossRef]

72. Wang, Y.C. Promoting collaborative writing through wikis: A new approach for advancing innovative and active learning in an ESP context. Comput. Assist. Lang. Learn. 2015, 28, 499-512. [CrossRef] 
73. Aydın, Z.; Yıldız, S. Using wikis to promote collaborative EFL writing. Lang. Learn. Technol. 2014, 18, $160-180$.

74. Abrams, Z.I. Collaborative writing and text quality in Google Docs. Lang. Learn. Technol. 2019, 23, $22-42$.

75. Abrams, Z. Exploring collaboratively written L2 texts among first-year learners of German in Google Docs. Comput. Assist. Lang. Learn. 2016, 29, 1259-1270. [CrossRef]

76. Ebadi, S.; Rahimi, M. Exploring the impact of online peer-editing using Google Docs on EFL learners' academic writing skills: A mixed methods study. Comput. Assist. Lang. Learn. 2017, 30, 787-815. [CrossRef]

77. Sauro, S.; Sundmark, B. Critically examining the use of blog-based fanfiction in the advanced language classroom. ReCALL 2019, 31, 40-55. [CrossRef]

78. Pham, V.P.H.; Usaha, S. Blog-based peer response for L2 writing revision. Comput. Assist. Lang. Learn. 2016, 29, 724-748. [CrossRef]

79. Sun, Y.C.; Chang, Y.J. Blogging to learn: Becoming EFL academic writers through collaborative dialogues. Lang. Learn. Technol. 2012, 16, 43-61.

80. Kessler, G.; Bikowski, D.; Boggs, J. Collaborative writing among second language learners in academic web-based projects. Lang. Learn. Technol. 2012, 16, 91-109.

81. Hung, S.T.A.; Huang, H.T.D. Blogs as a learning and assessment instrument for English-speaking performance. Interact. Learn. Environ. 2016, 24, 1881-1894. [CrossRef]

82. Huang, H.C. From web-based readers to voice bloggers: EFL learners' perspectives. Comput. Assist. Lang. Learn. 2015, 28, 145-170. [CrossRef]

83. Elola, I. Collaborative writing: Fostering foreign language and writing conventions development. Lang. Learn. Technol. 2010, 14, 51-71.

84. Kessler, G.; Bikowski, D. Developing collaborative autonomous learning abilities in computer mediated language learning: Attention to meaning among students in wiki space. Comput. Assist. Lang. Learn. 2010, 23, 41-58. [CrossRef]

85. Boulos, M.N.K.; Maramba, I.; Wheeler, S. Wikis, blogs and podcasts: A new generation of Web-based tools for virtual collaborative clinical practice and education. BMC Med. Educ. 2006, 6, 41. [CrossRef]

86. Parker, K.; Chao, J. Wiki as a teaching tool. Interdiscip. J. E-Learn. Learn. Objects 2007, 3, 57-72.

87. Alyousef, H.S.; Picard, M.Y. Cooperative or collaborative literacy practices: Mapping metadiscourse in a business students' wiki group project. Australas. J. Educ. Technol. 2011, 27, 463-480. [CrossRef]

88. Bikowski, D.; Vithanage, R. Effects of web-based collaborative writing on individual L2 writing development. Lang. Learn. Technol. 2016, 20, 79-99.

89. Wolfe, J. Annotation technologies: A software and research review. Comput. Compos. 2002, 19, 471-497. [CrossRef]

90. Ramezanali, N.; Faez, F. Vocabulary learning and retention through multimedia glossing. Lang. Learn. Technol. 2019, 23, 105-124.

91. Yeh, S.W.; Lo, J.J.; Chu, H.M. Application of online annotations to develop a web-based Error Correction Practice System for English writing instruction. System 2014, 47, 39-52. [CrossRef]

92. Türk, E.; Erçetin, G. Effects of interactive versus simultaneous display of multimedia glosses on L2 reading comprehension and incidental vocabulary learning. Comput. Assist. Lang. Learn. 2014, 27, 1-25. [CrossRef]

93. Tseng, S.S.; Yeh, H.C. Integrating reciprocal teaching in an online environment with an annotation feature to enhance low-achieving students' English reading comprehension. Interact. Learn. Environ. 2018, 26, 789-802. [CrossRef]

94. Hu, S.M.; Vongpumivitch, V.; Chang, J.S.; Liou, H.C. The effects of L1 and L2 e-glosses on incidental vocabulary learning of junior high-school English students. ReCALL 2014, 26, 80-99. [CrossRef]

95. Malekzadeh, M.; Mustafa, M.B.; Lahsasna, A. A review of emotion regulation in intelligent tutoring systems. J. Educ. Technol. Soc. 2015, 18, 435-445.

96. Choi, I.C. Efficacy of an ICALL tutoring system and process-oriented corrective feedback. Comput. Assist. Lang. Learn. 2016, 29, 334-364. [CrossRef]

97. Allen, L.K.; Crossley, S.A.; Snow, E.L.; McNamara, D.S. L2 writing practice: Game enjoyment as a key to engagement. Lang. Learn. Technol. 2014, 18, 124-150.

98. Chang, Y.H.; Liu, T.C.; Paas, F. Cognitive resources allocation in computer-mediated dictionary assisted learning: From word meaning to inferential comprehension. Comput. Educ. 2018, 127, 113-129. [CrossRef]

99. Knight, S. Dictionary use while reading: The effects on comprehension and vocabulary acquisition for students of different verbal abilities. Mod. Lang. J. 1994, 78, 285-299. [CrossRef] 
100. Wang, J. The use of e-dictionary to read e-text by intermediate and advanced learners of Chinese. Comput. Assist. Lang. Learn. 2012, 25, 475-487. [CrossRef]

101. Karras, J.N. The effects of data-driven learning upon vocabulary acquisition for secondary international school students in Vietnam. ReCALL 2016, 28, 166-186. [CrossRef]

102. Liu, T.C.; Fan, M.H.M.; Paas, F. Effects of digital dictionary format on incidental acquisition of spelling knowledge and cognitive load during second language learning: Click-on vs. key-in dictionaries. Comput. Educ. 2014, 70, 9-20. [CrossRef]

103. Liu, T.C.; Lin, P.H. What comes with technological convenience? Exploring the behaviors and performances of learning with computer-mediated dictionaries. Comput. Hum. Behav. 2011, 27, 373-383. [CrossRef]

104. Tono, Y. Application of eye-tracking in EFL learners' dictionary look-up process research. Int. J. Lexicogr. 2011, 24, 124-153. [CrossRef]

105. Lin, Y.J.; Wang, H.C. Using enhanced OER videos to facilitate English L2 learners' multicultural competence. Comput. Educ. 2018, 125, 74-85. [CrossRef]

106. Hsu, C.K. Learning motivation and adaptive video caption filtering for EFL learners using handheld devices. ReCALL 2015, 27, 84-103. [CrossRef]

107. Hsu, W. The effects of audiovisual support on EFL learners' productive vocabulary. ReCALL 2014, 26, 62-79. [CrossRef]

108. Chou, I.C. Reading for the purpose of responding to literature: EFL students' perceptions of e-books. Comput. Assist. Lang. Learn. 2016, 29, 1-20. [CrossRef]

109. Liu, Y.T.; Leveridge, A.N. Enhancing L 2 vocabulary acquisition through implicit reading support cues in e-books. Br. J. Educ. Technol. 2017, 48, 43-56. [CrossRef]

110. Chan, C.H.Y. Building an online library for interpretation training: Explorations into an effective blended-learning mode. Comput. Assist. Lang. Learn. 2014, 27, 454-479. [CrossRef]

111. Blommaert, J. Bernstein and poetics revisited: Voice, globalization and education. Discourse Soc. 2008, 19, 425-451. [CrossRef]

112. Tecedor, M.; Campos-Dintrans, G. Developing oral communication in Spanish lower-level courses: The case of voice recording and videoconferencing activities. ReCALL 2019, 31, 116-134. [CrossRef]

113. Azuma, R.T. A survey of augmented reality. Presence Teleoper. Virtual Environ. 1997, 6, 355-385. [CrossRef]

114. Hsu, T.C. Learning English with augmented reality: Do learning styles matter? Comput. Educ. 2017, 106, 137-149. [CrossRef]

115. Ho, S.C.; Hsieh, S.W.; Sun, P.C.; Chen, C.M. To activate English learning: Listen and speak in real life context with an AR featured u-learning system. J. Educ. Technol. Soc. 2017, 20, 176-187.

116. Hong, Z.W.; Huang, Y.M.; Hsu, M.; Shen, W.W. Authoring robot-assisted instructional materials for improving learning performance and motivation in EFL classrooms. J. Educ. Technol. Soc. 2016, 19, 337-349.

117. Mazzoni, E.; Benvenuti, M. A robot-partner for preschool children learning English using socio-cognitive conflict. J. Educ. Technol. Soc. 2015, 18, 474-485.

118. Wu, W.C.V.; Wang, R.J.; Chen, N.S. Instructional design using an in-house built teaching assistant robot to enhance elementary school English-as-a-foreign-language learning. Interact. Learn. Environ. 2015, 23, 696-714. [CrossRef]

119. Barber, M.; Njus, D. Clicker evolution: Seeking intelligent design. CBE Life Sci. Educ. 2007, 6, 1-8. [CrossRef]

120. Pearson, R.J. Tailoring Clicker Technology to Problem-Based Learning: What's the Best Approach? J. Chem. Educ. 2017, 94, 1866-1872. [CrossRef]

121. Roussel, S.; Galan, J.P. Can clicker use support learning in a dual-focused second language German course? Lang. Learn. Technol. 2018, 22, 45-64.

122. Kent, D. Technique efficacy when using a student response system in the reading classroom. Lang. Learn. Technol. 2019, 23, 26-35.

123. Patel, M.S.; Asch, D.A.; Volpp, K.G. Wearable devices as facilitators, not drivers, of health behavior change. JAMA 2015, 313, 459-460. [CrossRef]

124. Bower, M.; Sturman, D. What are the educational affordances of wearable technologies? Comput. Educ. 2015, 88, 343-353. [CrossRef] 
125. De la Guía, E.; Camacho, V.L.; Orozco-Barbosa, L.; Luján, V.M.B.; Penichet, V.M.; Pérez, M.L. Introducing IoT and wearable technologies into task-based language learning for young children. IEEE Trans. Learn. Technol. 2016, 9, 366-378. [CrossRef]

126. Shadiev, R.; Hwang, W.Y.; Liu, T.Y. A study of the use of wearable devices for healthy and enjoyable English as a Foreign language learning in authentic contexts. J. Educ. Technol. Soc. 2018, 21, 217-231. 